\title{
Increased Risk of Ocular Hypertension in Patients with Cushing's Disease: An Underestimated Comorbidity
}

\section{Zhengyuan Chen}

Huashan Hospital Fudan University

\section{Yichen Ma}

Huashan Hospital Fudan University

\section{Zengyi Ma}

Huashan Hospital

\section{Zhao Ye}

Huashan Hospital Fudan University

\section{Wenqiang $\mathrm{He}$}

Huashan Hospital Fudan University

\section{Qilin Zhang}

Huashan Hospital Fudan University

\section{Min $\mathrm{He}$}

Huashan Hospital Fudan University

Hongying Ye

Huashan Hospital Fudan University

\section{Zhaoyun Zhang}

Huashan Hospital Fudan University

\section{Yongfei Wang}

Huashan Hospital Fudan University

\section{Huiyin Yang}

Huashan Hospital Fudan University

\section{Zhaozeng Lu}

Huashan Hospital Fudan University

\section{Zhiliang Wang}

Huashan Hospital Fudan University

\section{Nidan Qiao}

Huashan Hospital https://orcid.org/0000-0001-5478-3555

\section{Yiqin Xiao ( $\nabla$ xiaoyiqin1028@163.com )}

Huashan Hospital, Shanghai

\section{Yao Zhao}




\section{Research article}

Keywords: hypercortisolemia, comorbidity, pituitary adenoma, ophthalmology

Posted Date: September 10th, 2020

DOl: https://doi.org/10.21203/rs.3.rs-64004/v1

License: (c) (i) This work is licensed under a Creative Commons Attribution 4.0 International License. Read Full License 


\section{Abstract}

\section{Background}

The association between ocular hypertension and endogenous hypercortisolemia, as well as the ophthalmological outcomes after endocrine remission due to a surgical resection were still unknown.

\section{Methods}

Intraocular pressure (IOP), visual field and peripapillary retinal nerve fiber layer thickness were documented in all patients with Cushing's disease (CD) admitted to a tertiary pituitary center for surgery from Jan to Jul 2019. Patients with acromegaly and patients with nonfunctioning pituitary adenoma (NFPA) during the same study period were served as controls. We calculated the odds ratio and identified risk factors of developing ocular hypertension, and presented postoperative trends of IOP.

Results

52 patients (38.4 \pm 12.4 years old) with CD were included. IOP was higher in patients with CD (left $19.4 \pm$ $5.4 \mathrm{mmHg}$ and right $20.0 \pm 7.1 \mathrm{mmHg}$ ) than patients with acromegaly (left $17.5 \pm 2.3 \mathrm{mmHg}$ and right $18.6 \pm 7.0 \mathrm{mmHg}, \mathrm{p}=0.033$ ) and patients with NFPA (left 17.8 $\pm 2.6 \mathrm{mmHg}$ and right $17.4 \pm 2.4 \mathrm{mmHg}, \mathrm{p}$ $=0.005) .21$ eyes $(20.2 \%)$ in patients with CD were diagnosed with ocular hypertension comparing to 4 eyes $(4.7 \%)$ in the acromegaly group and 4 eyes $(4.5 \%)$ in the NFPA group. The odds ratio of developing ocular hypertension in patients with CD was $5.1(95 \% \mathrm{Cl}, 1.3-25.1, \mathrm{p}=0.029)$ and $6.6(95 \% \mathrm{Cl}, 1.8-$ $30.3, p=0.007)$, comparing with the two control groups, respectively. Among patients with $C D$, those with higher urine free cortisol were more likely to develop ocular hypertension (OR 19.4, 95\% Cl $1.7-72.6$ ). IOP decreased at one-month follow-up in patients with $C D$ and the change sustained at three-month followup.

\section{Conclusions}

In conclusion, patients with $\mathrm{CD}$ had increased risk of developing ocular hypertension comparing to other types of pituitary adenomas, which warrant the discretion of both ophthalmologists and neuroendocrinologists.

\section{Background}

Cushing's disease (CD) is characterized by hypercortisolism resulting from a corticotroph pituitary adenoma that secretes excessive adrenocorticotrophic hormone (ACTH). Common clinical symptoms and signs of $C D$ include weight gain, centripetal fat deposition, cutaneous striae, skin thinning, muscle wasting, and fatigue ${ }^{1,2}$. Hypercortisolism-related comorbidities (diabetes mellitus, hypertension, cardiovascular disease, and deep venous thrombosis) may result in severe complications and a high mortality rate ${ }^{3,4}$. 
The majority of CD encountered in clinics were usually a small tumor, namely microadenoma. Visual dysfunction due to tumor compressing was not commonly seen in these patients. As the largest tertiary pituitary center in South China, we encountered many patients who had glaucoma surgeries performed and then referred to our center for endocrine evaluation. It was well known that systemic steroid was a significant risk factor for increased intraocular pressure (IOP) ${ }^{5,6}$, and the incidence may rise to $30-40 \%$

of the general population due to topical or systemic glucocorticoids usage ${ }^{7,8}$. However, only several case reports and two cohort studies ${ }^{9-11}$ investigated the association between increased IOP and endogenous hypercortisolemia. The association between glaucoma and excessive endogenous cortisol, as well as the ophthalmological outcomes after endocrine remission due to a surgical resection were still unknown.

We hypothesized that the risk of developing ocular hypertension was increased in patients with $C D$. We compared the ocular manifestation in patients with $C D$ with two control groups: patients with growth hormone secreting pituitary adenomas (acromegaly), and patients with clinically nonfunctioning pituitary adenomas (NFPA), in an attempt to distinguish endocrine- as opposed to tumor-related effects.

\section{Methods}

\section{Cohorts}

We recorded clinical data of all patients with CD admitted to Huashan Hospital for surgery from Jan to July 2019. Patients who had underwent glaucoma treatment were excluded. We also included two control groups: control group I included randomly selected acromegalic patients, and control group II included randomly selected patients with NFPA who underwent pituitary surgery in our institution during the same study period. The study was approved by the Huashan Hospital Institutional Review Board and was conducted under the ethical standards of the Declaration of Helsinki. All the patients provided written, informed consent to participate in our study when their clinical data were recorded.

\section{Definition of Cushing's disease and the control groups}

The diagnosis of Cushing's syndrome was based on the following criteria: elevated 24-hour urinary free cortisol (24 h UFC) above the upper limit of the reference range, and/or lack of serum cortisol suppression after $1 \mathrm{mg}$ dexamethasone in the absence of other exogenous glucocorticoid use. ACTH-dependent hypercortisolism of pituitary origin (CD) was confirmed by normal or elevated preoperative plasma ACTH concentrations and at least one of the following: (a) immunopathology confirming the diagnosis; (b) clinical and endocrine remission after pituitary surgery; (c) preoperative bilateral inferior petrosal sinus sampling predicting a pituitary source ${ }^{12}$.

The diagnosis of acromegaly was based on the symptoms, elevated growth hormone (GH) or insulin growth factor-1 (IGF-1) level, and postoperative pathological confirmation. The diagnosis of an NFPA was based on the postoperative pathological confirmation of a pituitary adenoma in the absent endocrinological or clinical evidence of a functional tumor. 


\section{Ophthalmological examinations and definitions}

All patients underwent the following eye examinations: best correct visual acuity, IOP using noncontact tonometry, slit-lamp examination of the anterior, and ophthalmoscope examination of the posterior segment. The visual field was identified by static perimetry in a threshold approach (SITA Standard 30 2, Humphrey Field Analyser II, Carl Zeiss Meditec Inc., Australia). Peripapillary retinal nerve fiber layer ( $p$ RNFL) thickness was measured by optical coherence tomography (OCT) images (DRI OCT Triton, Topcon, Japan) using three-dimensional disc and optic nerve head protocols.

Ocular hypertension was diagnosed if intraocular pressure was higher than $21 \mathrm{mmHg}{ }^{13}$. A typical glaucomatous visual field damage was diagnosed by a cluster of 3 or more adjacent points in a typical localization for glaucoma with $p<5 \%$ in pattern standard deviation and for one of them with $p<1 \%$ in pattern standard deviation ${ }^{14}$. IOP and visual field tests during follow-up were carried out at one-month and three-month after surgical resection.

\section{Other factors}

We identified baseline characteristics, including age, gender, height, weight, and major comorbidities (hypertension, diabetes mellitus). We recorded tumor size (no visible tumor, microadenoma or macroadenoma) and the presence of cavernous sinus invasion on magnetic resonance imaging (MRI). In patients with $\mathrm{CD}$, we recorded morning ACTH and $24 \mathrm{~h}$ UFC. In addition to preoperative cortisol and ACTH data, we recorded information on free thyroxine (T4) and free triiodothyronine levels (T3) in all patients. Repeat testing of fasting morning cortisol was obtained consecutively after the operation. Postoperative serum cortisol levels were consistent with a remission, in case of low early morning serum cortisol concentrations ( $<1.8 \mathrm{ug} / \mathrm{dL})$.

\section{Statistical methods}

Continuous variables are expressed as mean $\pm S D$, and categorical variables are expressed as numbers and proportions. We calculated the odds ratio of developing ocular hypertension after adjusting for plausible confounders (age, gender, BMI, T3, and T4) using general estimating equations to account for inter-eye correlation. Postoperative trends of intraocular pressure are presented in patients with $C D$ and patients with acromegaly. All the analysis was completed by $\mathrm{R}$ software version 3.4.2.

\section{Results}

We identified 54 patients with $C D$ and excluded 2 patients for a previous glaucoma surgery. We included 52 patients (38.4 \pm 12.4 years old) with CD, 43 patients with acromegaly, and another 44 patients with NFPA in this study. Clinical characteristics, radiological assessment, endocrine tests are listed in Table 1. The majority of patients with CD were female (78.8\%), had hypertension (63.4\%), and were with a microadenoma (92.3\%). $24 \mathrm{~h}$ UFC elevated in all these patients with normal or elevated ACTH. Comparing 
to patients with acromegaly or NFPA, patients with CD were younger, more likely to be female, more likely to have hypertension or diabetes mellitus, and less likely to harbor a macroadenoma. 
Table 1

Basic characteristics and ocular manifestation in patients with different type of pituitary adenomas

Patients with CD Patients with acromegaly

Patients with NFPA

$(\mathrm{N}=52) \quad(\mathrm{N}=43) \quad(\mathrm{N}=44)$

Age (years old)

$38.4 \pm 12.4$

$47.3 \pm 12.6$

$49.3 \pm 13.7$

Gender (Female)

$41(78.8 \%)$

$20(46.6 \%)$

21 (47.7)

Body mass index $\left(\mathrm{kg} / \mathrm{m}^{2}\right)$

$25.5 \pm 4.3$

$25.5 \pm 3.6$

$24.4 \pm 3.4$

Comorbidities

Diabetes Mellitus

19 (36.5\%)

$14(32.6 \%)$

$8(18.2 \%)$

Hypertension

$33(63.4 \%)$

$14(32.6 \%)$

$6(13.6 \%)$

Tumor characteristics

Macroadenoma

$4(7.7 \%)$

$34(79.1 \%)$

$39(88.6 \%)$

Microadenoma

48 (92.3\%)

$9(20.9 \%)$

$5(11.4 \%)$

Nonequivocal tumor

28/48 (58.3\%)

NA

NA

Equivocal tumor

20/48 (41.7\%)

NA

NA

CS invasiveness

$2(3.8 \%)$

11 (25.6\%)

$12(27.3 \%)$

Endocrinological tests

ACTH (pg/ml)

65 [44-97]

NA

NA

24 h UFC (ULN)

$3.3[2.0-6.1]$

NA

NA

$\mathrm{GH}(\mathrm{ng} / \mathrm{ml})$

NA

$10.4[4.8-22.8]$

NA

IGF-1 (ULN)

NA

$2.4[1.7-3.1]$

NA

Free T4 (pmol/l)

$14.7 \pm 2.9$

$19.2 \pm 3.7$

$12.5 \pm 3.2$

Free T3 (pmol/l)

$3.4 \pm 0.8$

$4.8 \pm 0.9$

$4.0 \pm 0.6$

Intraocular pressure $(\mathrm{mmHg})$

Left

$19.4 \pm 5.4$

$17.5 \pm 2.3$

$17.8 \pm 2.6$

Right

$20.0 \pm 7.1$

$18.6 \pm 7.0$

$17.4 \pm 2.4$

Ocular hypertension

Left

$9(17.3 \%)$

$3(7.0 \%)$

$2(4.5 \%)$

CD: Cushing's Disease, NFPA: nonfunctioning pituitary adenoma, CS: cavernous sinus, ACTH: adrenocorticotropic hormone, UFC: urine free cortisol, GH: growth hormone, IGF-1: insulin growth factor-1, NA: not available 


\begin{tabular}{|llll|}
\hline & $\begin{array}{l}\text { Patients with CD } \\
(\mathbf{N}=\mathbf{5 2})\end{array}$ & $\begin{array}{l}\text { Patients with acromegaly } \\
\mathbf{( N = 4 3 )}\end{array}$ & $\begin{array}{l}\text { Patients with NFPA } \\
\mathbf{( N = 4 4 )}\end{array}$ \\
\hline Right & $12(23.1 \%)$ & $1(2.3 \%)$ & $2(4.5 \%)$ \\
\hline Glaucomatous visual field & & & $0(0.0 \%)$ \\
\hline Left & $3(5.8 \%)$ & $0(0.0 \%)$ & $0(0.0 \%)$ \\
\hline Right & $4(7.7 \%)$ & $0(0.0 \%)$ & \\
\hline $\begin{array}{l}\text { CD: Cushing's Disease, NFPA: nonfunctioning pituitary adenoma, CS: cavernous sinus, ACTH: } \\
\text { adrenocorticotropic hormone, UFC: urine free cortisol, GH: growth hormone, IGF-1: insulin growth } \\
\text { factor-1, NA: not available }\end{array}$ & \\
\hline
\end{tabular}

Intraocular pressure was higher in patients with CD (left $19.4 \pm 5.4 \mathrm{mmHg}$ and right $20.0 \pm 7.1 \mathrm{mmHg}$ ) than in patients with acromegaly (left $17.5 \pm 2.3 \mathrm{mmHg}$ and right $18.6 \pm 7.0 \mathrm{mmHg}, p=0.033$ ) and patients NFPA (left $17.8 \pm 2.6 \mathrm{mmHg}$ and right $17.4 \pm 2.4 \mathrm{mmHg}, \mathrm{p}=0.005$ ). Twenty-one eyes $(20.2 \%)$ in patients with $C D$ were diagnosed with ocular hypertension comparing to four eyes $(4.7 \%)$ in the acromegaly group and four eyes (4.5\%) in the NFPA group. Thus, the odds ratio of developing ocular hypertension in patients with CD was $5.1(95 \% \mathrm{Cl}, 1.3-25.1, \mathrm{p}=0.029)$ and $6.6(95 \% \mathrm{Cl}, 1.8-30.3, \mathrm{p}=$ 0.007), compared with patients with acromegaly and patients with NFPA, respectively. Seven eyes (four patients, $6.7 \%$ ) with ocular hypertension had glaucomatous visual field damage in patients with CD, but none of the eyes in the acromegaly group or the NFPA group.

We also compared the thickness of p-RNFL in patients with CD and patients with acromegaly but did not observe statistical difference between the two groups (average RNFL, $109.6 \mu \mathrm{m}$ in CD and $113.0 \mu \mathrm{m}$ in acromegaly, $\mathrm{p}=0.153$; superior RNFL, $132.2 \mu \mathrm{m}$ in $\mathrm{CD}$ and $138.6 \mu \mathrm{m}$ in acromegaly, $\mathrm{p}=0.099$, inferior $\mathrm{RNFL}, 142.7 \mu \mathrm{m}$ in $\mathrm{CD}$ and $146.5 \mu \mathrm{m}$ in acromegaly, $\mathrm{p}=0.288$ )

Figure 1 illustrated a typical patient with CD who was diagnosed with IOP. A 40 years old female with central obesity and skin striae was admitted to our center. She was diagnosed with hypertension and osteoporosis five years ago. Pre-operation evaluations confirmed pituitary-originated hypercortisolemia with increased $24 \mathrm{~h}$ UFC higher than three folds of the normal upper limit. Preoperative MRI and intraoperative findings confirmed a tumor located on the left side of the pituitary. The patient had increased IOP to $25 \mathrm{mmHg}$ on the left eye, and the visual field demonstrated nasal scotoma. P-RNFL was within the normal range. IOP on the right eye increased to $50 \mathrm{mmHg}$ and was suspected blind due to glaucoma.

We further investigated the risk factors for developing ocular hypertension in patients with CD. We regressed the outcome (patients developing ocular hypertension) on possible risk factors (age, gender, $\mathrm{BMI}$, comorbidities, tumor characteristics, endocrine tests) and found that only $24 \mathrm{~h}$ UFC was associated with ocular hypertension $(p=0.025)$. Patients with $24 \mathrm{~h}$ UFC higher than three folds of the normal upper 
limit were more likely to develop ocular hypertension than patients who had lower $24 \mathrm{~h}$ UFC (OR 19.4, 95\% Cl 1.7-72.6).

The majority of the patients with CD had remission (49/52, 94.3\%) after surgical treatment. We further reviewed postoperative IOP change in patients with functional pituitary adenomas (Fig. 2). IOP decreased to $16.9 \pm 4.3 \mathrm{mmHg}$ in the left eye and $16.9 \pm 4.8 \mathrm{mmHg}$ in the right eye at one-month follow-up in patients with CD. Afterward, the IOP kept constant at three-month follow-up $(16.6 \pm 3.1 \mathrm{mmHg}$ in the left eye and $17.4 \pm 2.9 \mathrm{mmHg}$ in the right eye). While patients with acromegaly had constant IOP (left $16.5 \pm$ $2.4 \mathrm{mmHg}$ and right $16.6 \pm 2.2 \mathrm{mmHg}$ at one-month, left $16.8 \pm 2.3 \mathrm{mmHg}$ and right $16.8 \pm 2.2 \mathrm{mmHg}$ at three-month) throughout the presurgical and follow-up period. Among the 7 eyes with glaucomatous visual field damage, 6 eyes improved on the follow up visual field testing with one eye similar.

\section{Discussion}

In this prospective study, we documented that patients with Cushing's disease were more likely to develop ocular hypertension compared with patients with $\mathrm{GH}$-secreting pituitary adenoma and patients with nonfunctioning pituitary adenoma. The severity of the disease manifested by 24 -hour urine free cortisol was associated with the risk of developing ocular hypertension. Intraocular pressure decreased after cortisol level normalization due to surgical resection of the tumor.

The prevalence of increased IOP among the general population varied in different studies. It was reported to be $2.2 \%$ in an Indian cohort with a predominantly male composition, and the prevalence correlated with increased age ${ }^{15}$. The incidence was $1.4 \%$ from another study performed in a French cohort ${ }^{16}$. It was estimated that $7 \%$ of the adults aged 40 years and older in China had increased IOP ${ }^{17}$. The incidence of glaucoma was 3.5\% among the population from 40 to 80 years old in a global study performed in 2013 18. Age-standardized incidence of primary glaucoma was estimated to be $2.6 \%$ in the general population in China ${ }^{19}$. According to these data, our study suggested that the incidence of ocular hypertension was increased in patients with CD comparing to the general population.

Secondary glaucoma was usually caused by trauma, inflammation, or external glucocorticoid usage 20 . Previous studies suggested that externally applied corticosteroids increase the intraocular pressure in one-third of the general population ${ }^{5-8}$. The proposed mechanism of corticosteroid-induced glaucoma includes morphological and functional changes in the trabecular meshwork system and is similar to the pathogenesis of primary open-angle glaucoma ${ }^{21}$.

On the other hand, increased intraocular pressure in patients with endogenously elevated serum cortisol levels was not well studied. Sofia et al. reported a case with high intraocular pressure and subsequently diagnosed with $\mathrm{CD}^{9}$. The case had normalized IOP at one-year follow-up in a glaucoma clinic. Mishra et al. reported that seven out of 22 patients had increased IOP in the CD cohort ${ }^{11}$. Though they found mean serum cortisol level was lower in patients with normal IOP comparing to those with high IOP, the difference was not statistically significant. Jonas et al. screened 62 patients with CD and found four eyes 
had increased intraocular pressure before surgery ${ }^{10}$. However, they did not document any retinal nerve fiber layer change and any glaucomatous visual field change in those cohorts. Our study was similar to those previously reported studies by identifying endogenous hypercortisolemia as a risk factor for developing ocular hypertension. We also found that IOP was associated with disease severity and can be normalized after remission.

Though typical changes in patients with secondary glaucoma may include fundus change or RNFL thinning, we were not able to identify these changes. Short disease duration precludes any positive findings of RNFL thinning in these patients. Statistical comparison was also unavailable due to the limited sample size.

The results of this study informed ophthalmologists and neuroendocrinologists that in patients with ocular hypertension and glaucoma, endogenous hypercortisolemia should be considered. We have several limitations in this study. Patients with CD were more likely to develop diabetes mellitus and hypertension, which were not adjusted in the risk calculation. Nevertheless, we argued that diabetes mellitus and hypertension were not associated with ocular hypertension. We used a non-contact tonometer, which was not the gold standard for IOP measurement. Ideally, applanation tonometry should be used for IOP measurement ${ }^{22}$, but it was invasive and not routinely performed in our practice. We were not able to measure corneal thickness, which was associated with IOP ${ }^{23}$. Typically, IOP varies within 24 hours; thus, these patients should be investigated throughout this time cycle ${ }^{24}$. However, we argue that a 24-hour IOP monitoring might only increase the odds ratio observed in the current result.

\section{Conclusions}

In conclusion, patients with $C D$ had increased risk of developing ocular hypertension comparing to other types of pituitary adenomas, which warrant the discretion of both ophthalmologists and neuroendocrinologists. Intraocular pressure was reversible after resection of the tumor and restoration of the cortisol level.

\section{Abbreviations}

IOP: Intraocular pressure

CD: Cushing's disease

NFPA: nonfunctioning pituitary adenoma

ACTH: adrenocorticotrophic hormone

$\mathrm{GH}$ : growth hormone

IGF-1: insulin growth factor-1 
p-RNFL: Peripapillary retinal nerve fiber layer

OCT: optical coherence tomography

MRI: magnetic resonance imaging

\section{Declarations}

\section{Ethics approval and consent to participate:}

The study was approved by the Huashan Hospital Institutional Review Board and was conducted under the ethical standards of the Declaration of Helsinki. All the patients provided written, informed consent to participate in our study when their clinical data were recorded.

\section{Consent to publish:}

All the authors were consented for publishing this manuscript.

Availability of data and materials: Deidentified data would be available upon requested to the corresponding author.

\section{Competing interests:}

The authors declare that there are no conflict of interest that could be perceived as prejudicing the impartiality of the research reported.

\section{Funding:}

This study is supported by Shanghai Committee of Scientific and Technology, China (No. 19411961700). The fund supported data collection.

\section{Authors' Contributions:}

ZC and YM collected data; $Z M, Z Y, W H$, and QZ provided clinical data; $M H, H Y$, and ZZ provided endocrine data; $Y W, H Y, Z L$, and ZW provided follow-up of the participants; NQ analyzed data and draft the manuscript; $Y X$ and $Y Z$ revised the manuscript and provided comments; the manuscript was approved by all the authors.

\section{Acknowledgements:}

N/A

\section{References}

1. Kelsall A, Newell-Price J. Cushing's disease-from Minnie G to key issues in the early 21st century. Lancet Diabetes Endocrinol. 2019;7(12):959-964. https://doi.org/10.1016/S2213- 
8587(19)30343-2

2. Molitch ME. Diagnosis and Treatment of Pituitary Adenomas: A Review. JAMA. 2017; 317(5):516524. https://doi.org/10.1001/jama.2016.19699

3. Broersen LHA, van Haalen FM, Biermasz NR, Lobatto DJ, Verstegen MJT, van Furth WR, Dekkers OM, Pereira AM. Microscopic versus endoscopic transsphenoidal surgery in the Leiden cohort treated for Cushing's disease: surgical outcome, mortality, and complications. Orphanet J Rare Dis. 2019;14(1):64. https://doi.org/10.1186/s13023-019-1038-0.

4. Pivonello R, Isidori AM, De Martino MC, Newell-Price J, Biller BMK, Colao A. Complications of Cushing's syndrome: state of the art. Lancet Diabetes Endocrinol. 2016;4(7):611-629. https://doi.org/10.1016/S2213-8587(16)00086-3

5. Phulke S, Kaushik S, Kaur S, Pandav SS. Steroid-induced Glaucoma: An Avoidable Irreversible Blindness. J Curr Glaucoma Pract. 2017;11(2):67-72. https://doi.org/10.5005/jp-journals-I00281226

6. Wu A, Khawaja AP, Pasquale LR, Stein JD. A review of systemic medications that may modulate the risk of glaucoma. Eye (Lond). 2020;34(1):12-28. https://doi.org/10.1038/s41433-019-0603-z

7. Holland EJ, Fingeret M, Mah FS. Use of Topical Steroids in Conjunctivitis: A Review of the Evidence. Cornea. 2019;38(8):1062-1067. https://doi.org/10.1097/IC0.0000000000001982

8. Tripathi RC, Parapuram SK, Tripathi BJ, Zhong Y, Chalam KV. Corticosteroids and glaucoma risk. Drugs Aging. 1999;15(6):439-450. https://doi.org/10.2165/00002512-199915060-00004

9. Habib SN, Lin Z, Puvanachandra N. Ocular hypertension secondary to high endogenous steroid load in Cushing's disease. BMJ Case Rep. 2019;12(1):bcr-2018-226738. https://doi.org/10.1136/bcr-2018226738

10. Jonas JB, Huschle O, Koniszewski G, Buchfelder M, Fahlbusch R. Intraocular pressure in patients with Cushing's disease. Graefes Arch Clin Exp Ophthalmol. 1990;228(5):407-409. https://doi.org/10.1007/bf00927251

11. Mishra P, Singh AP, Kanaujia V, Agarwal R, Mishra P, Guleria A, Tripathi A. Intraocular pressure and its correlation with midnight plasma cortisol level in Cushing's disease and other endogenous Cushing's syndrome. Indian J Ophthalmol. 2017;65(9):826-829. https://doi.org/10.4103/ijo.IJO_684_15

12. Tritos NA, Biller BMK: Cushing's disease. In: Fliers E, Korbonits M, Romijn JA, (eds.). Handbook of Clinical Neurology, pp. 221-234. Elsevier, Cambridge (2014)

13. Boey PY, Mansberger SL. Ocular hypertension: an approach to assessment and management. Can J Ophthalmol. 2014;49(6):489-496. https://doi.org/10.1016/j.jcjo.2014.06.013

14. Infeld DA, O'Shea JG. Glaucoma: diagnosis and management. Postgrad Med J. 1998;74(878):70915. https://doi.org/10.1136/pgmj.74.878.709.

15. Panday M, George R, Asokan R, Ramesh SV, Velumuri L, Choudhari NS, Boddupalli SD, Sunil GT, Vijaya L. Six-year incidence of ocular hypertension in a South Indian population: the Chennai eye disease incidence study. Br J Ophthalmol. 2015;99(5):604-8. https://doi.org/10.1136/bjophthalmol2014-305714. 
16. Tchabi-Hounnou S, Agbahoungba L, Sounouvou I, Yehouessi L, Alamou S, Doutetien C, Bassabi SK. High intraocular pressure and open angle glaucoma. Journal francais d'ophtalmologie. 2012;35:523528. https://doi.org/10.1016/j.jfo.2011.10.008.

17. Cui Y, Yang X, Zhang G, Guo H, Zhang M, Zhang L, Zeng J, Liu Q, Zhang L, Meng Q. Intraocular Pressure in General and Diabetic Populations From Southern China: the Dongguan Eye Study. Invest Ophthalmol Vis Sci. 2019;60(2):761-769. https://doi.org/10.1167/iovs.18-25247.

18. Quigley HA, Broman AT. The number of people with glaucoma worldwide in 2010 and $2020 \mathrm{Br} \mathrm{J}$ Ophthalmol. 2006;90(3):262-267. https://doi.org/10.1136/bjo.2005.081224

19. Lee JWY, Chan PP, Zhang X, Chen LJ, Jonas JB. Latest Developments in Normal-Pressure Glaucoma: Diagnosis, Epidemiology, Genetics, Etiology, Causes and Mechanisms to Management. Asia Pac J Ophthalmol (Phila). 2019;8(6):457-468. https://doi.org/10.1097/01.AP0.0000605096.48529.9c

20. Bai HQ, Yao L, Wang DB, Jin R, Wang YX. Causes and treatments of traumatic secondary glaucoma. Eur J Ophthalmol. 2009;19(2):201-206. https://doi.org/10.1177/112067210901900205

21. Tektas OY, Lütjen-Drecoll E. Structural changes of the trabecular meshwork in different kinds of glaucoma. Exp Eye Res. 2009;88(4):769-775. https://doi.org/10.1016/j.exer.2008.11.025

22. Bhartiya S, Gangwani M, Kalra RB, Aggarwal A, Gagrani M, Sirish KN. 24-hour Intraocular pressure monitoring: the way ahead. Rom J Ophthalmol. 2019;63(4):315-320.

23. Fayed MA, Chen TC. Pediatric intraocular pressure measurements: Tonometers, central corneal thickness, and anesthesia. Surv Ophthalmol. 2019;64(6):810-825. https://doi.org/10.1016/j.survophthal.2019.05.003

24. Ho CH, Wong JKW. Role of 24-Hour Intraocular Pressure Monitoring in Glaucoma Management. J Ophthalmol. 2019;3632197. https://doi.org/10.1155/2019/3632197

\section{Figures}


A
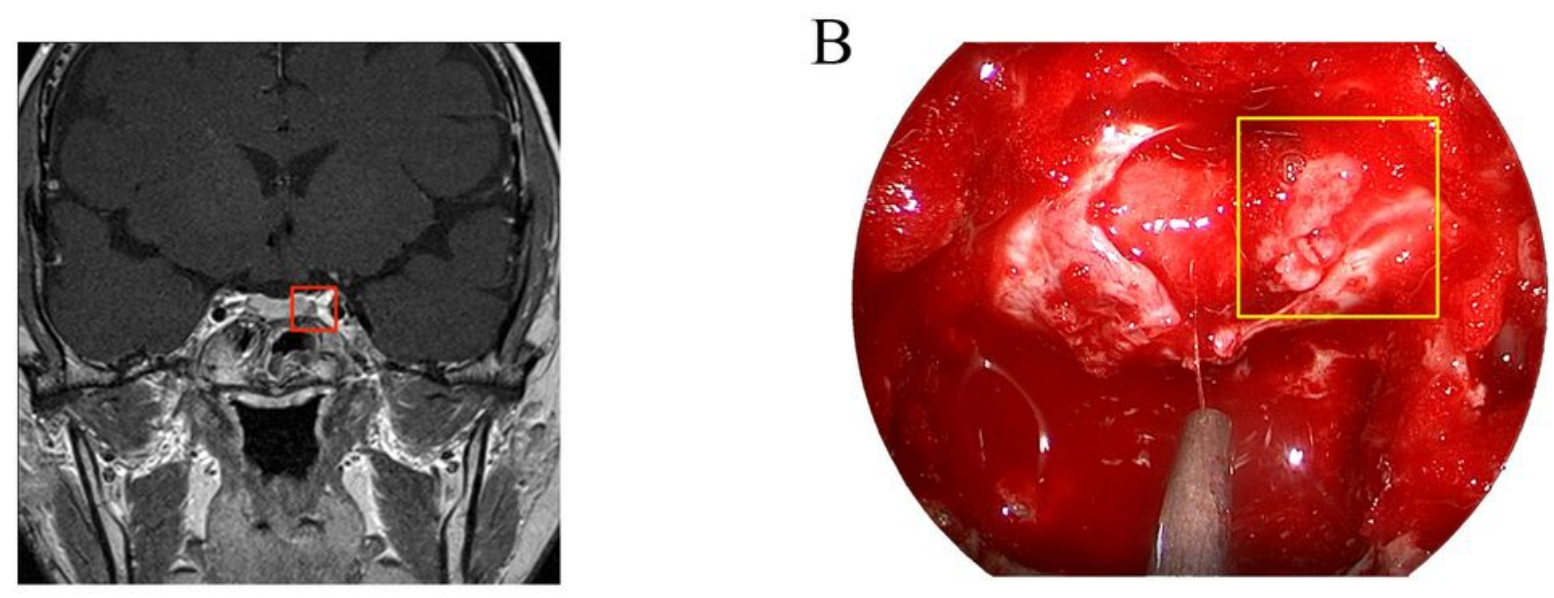

$\mathrm{C}$

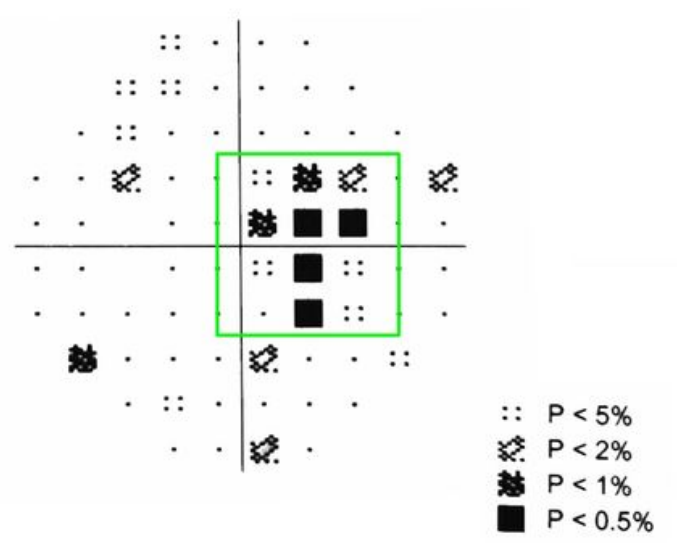

$\mathrm{D}$

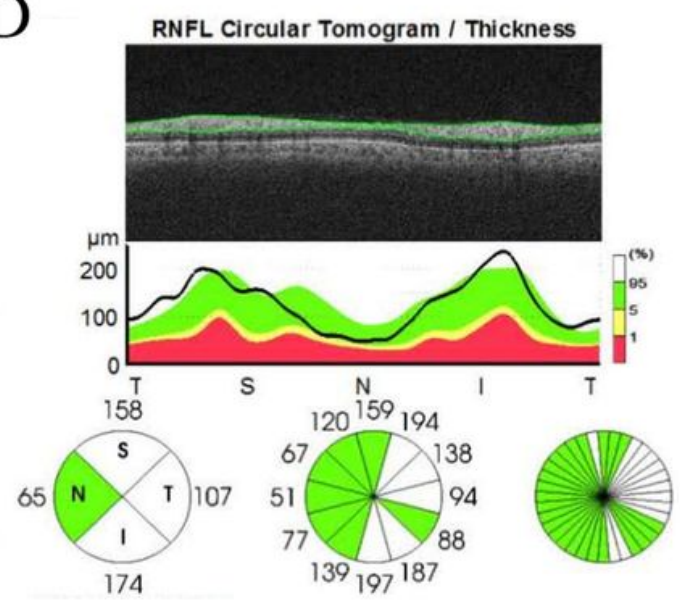

\section{Figure 1}

Illustration of a typical patient with Cushing's disease and was diagnosed with glaucoma. A, pre-operative T1W MRI shows an equivocal microadenoma on the left pituitary gland (red box); $B$, intraoperative snapshots of the tumor (yellow box); C, glaucomatous change of the visual field with a cluster of 3 or more adjacent points in a typical localization for glaucoma, with $p<5 \%$ in PSD, and for one of them with $p<1 \%$ in PSD (green box); D, p-RNFL was within the normal range. 

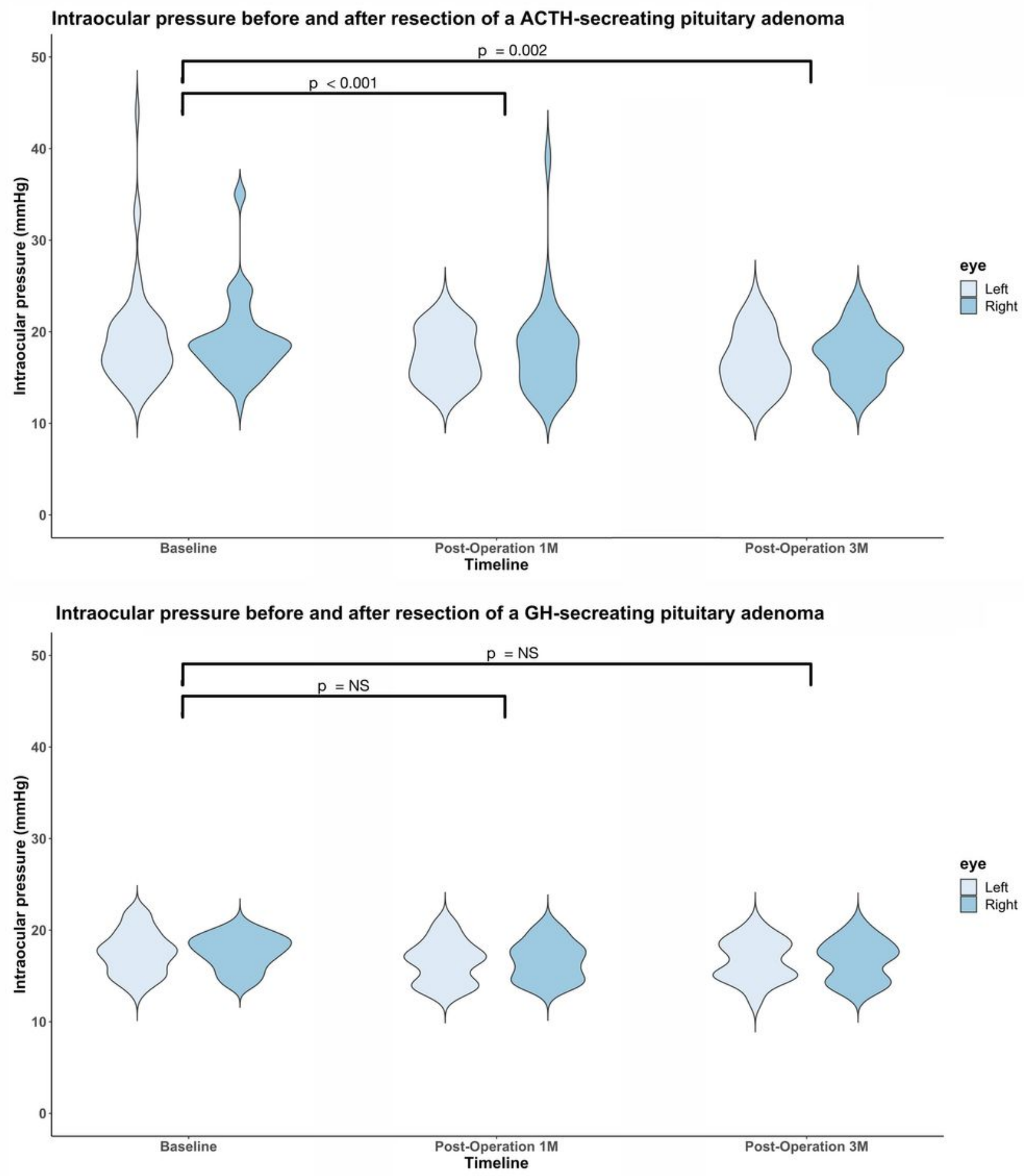

\section{Figure 2}

Violin plot of intraocular pressure before and after resection of an ACTH-secreting and $\mathrm{GH}$ - secreting pituitary adenoma.

\section{Supplementary Files}


This is a list of supplementary files associated with this preprint. Click to download.

- STROBEchecklistcohort.docx 